\title{
Avaliação de um kit didático que reproduz tatilmente ilustrações no ensino de Física
}

\author{
Evaluation of an Educational Kit that Tactually Reproduces llustrations in \\ Physical Teaching
}

Evaluación de un kit didáctico que reproduce tatilmente ilustraciones en la enseñanza de Física

\author{
* Josiane Pereira Torres \\ Doutoranda em Educação Especial pela Universidade Federal de São Carlos, São Carlos, São Paulo, \\ Brasil. \\ jtfisica@gmail.com
}

\section{** Enicéia Gonçalves Mendes}

Professora doutora da Universidade Federal de São Carlos, São Carlos, São Paulo, Brasil. eniceia.mendes@gmail.com

Recebido: 29 de outubro de 2015

Aprovado: 08 de junho de 2016

\section{RESUMO}

Nesse trabalho apresentamos resultados de uma pesquisa de mestrado cujo objetivo foi desenvolver e avaliar um kit didático, denominado de KitFis, que reproduz tatilmente ilustrações de fenômenos e situações no ensino da Física. Após o desenvolvimento do kit, foi realizado uma avaliação na qual três professores de física ministraram uma aula de determinado tema de física à um estudante cego, apenas com o apoio do kit. As aulas foram filmadas a fim de analisar o manuseio do kit pelos participantes e após as aulas os participantes foram entrevistados no intuito de levantarmos suas impressões com relação ao uso do kit. Os resultados mostraram que o kit permite a construção de uma quantidade significativa de ilustrações de situações físicas e ainda o estudante relatou que tais ilustrações foram percebidas com facilidade pelo tato, o que evidencia a qualidade tátil das peças do KitFis. O KitFis pode contribuir consideravelmente com práticas mais inclusivas no ensino regular possibilitando que estudantes cegos tenham acesso ao currículo assim como os demais estudantes.

Palavras-chave: Cegueira; Ensino de Física; Inclusão escolar; Educação Especial.

\section{ABSTRACT}

In this work we present results of a master's research whose objective was to develop and evaluate a didactic kit, called KitFis, that reproduces illustrations of phenomena and situations in the teaching of Physics. After the development of the kit, an evaluation was 
carried out in which three physics teachers gave a lesson of a certain physics subject to a blind student, only with the support of the kit. The classes were filmed in order to analyze the kit's handling by the participants and after the classes the participants were interviewed in order to get their impressions regarding the use of the kit. The results showed that the kit allows the construction of a significant amount of illustrations of physical situations and also the student reported that such illustrations were easily perceived by the touch, which shows the tactile quality of KitFis parts. KitFis can contribute considerably to more inclusive practices in regular education by enabling blind students to access the curriculum as well as other students.

keywords: Blindness; Physics Teaching; School inclusion; Special education.

\section{RESUMEN}

En este trabajo presentamos resultados de una investigación de maestría cuyo objetivo fue desarrollar y evaluar un kit didáctico, denominado de KitFis, que reproduce tatilmente ilustraciones de fenómenos y situaciones en la enseñanza de la Física. Después del desarrollo del kit, se realizó una evaluación en la que tres profesores de física impartieron una clase de determinado tema de física a un estudiante ciego, sólo con el apoyo del kit. Las clases fueron filmadas a fin de analizar el manejo del kit por los participantes y después de las clases los participantes fueron entrevistados con el propósito de levantar sus impresiones con relación al uso del kit. Los resultados mostraron que el kit permite la construcción de una cantidad significativa de ilustraciones de situaciones físicas y aún el estudiante relató que tales ilustraciones fueron percibidas con facilidad por el tacto, lo que evidencia la calidad táctil de las piezas del KitFis. El KitFis puede contribuir considerablemente con prácticas más inclusivas en la enseñanza regular posibilitando que los estudiantes ciegos tengan acceso al currículo así como a los demás estudiantes.

Palabras clave: Ceguera; Enseñanza de Física; Inclusión escolar; Educación Especial.

\section{Introdução}

A política de inclusão escolar contribuiu para que a matrícula do estudante público alvo da educação especial (PAEE) em escolas regulares se tornasse uma realidade. Os dados dos últimos censos (INEP, 2010, 2011, 2012, 2013 e 2014) escolares evidenciam essa afirmação, no ano de 2010 havia 484.332 matrículas passando para 558.423 no ano de 2011, 620.777 no ano de 2012, 648.921 matrículas no ano de 2013 e no ano de 2014 foi registrado um total de 698.768 matrículas de estudantes PAEE no ensino comum. Esses números mostram que tais estudantes estão ocupando os bancos das escolas comuns, porém a permanência com qualidade é o principal desafio na atualidade. Isso porque entende-se que mais importante que incluir o estudante PAEE na sala de aula regular é fornecer todos os recursos necessários para sua permanência com qualidade. Desde os 
recursos pedagógicos que auxiliam o acesso ao currículo escolar até os recursos que visam romper barreiras arquitetônicas e de acessibilidade.

Porém, mesmo sendo um direito garantido por lei (BRASIL, 1988) a permanência dos estudantes PAEE em escolas regulares ainda apresenta obstáculos que comprometem o pleno acesso ao currículo escolar por parte desses estudantes. Obstáculos de natureza arquitetônicas presentes no ambiente escolar os quais comprometem o ir e vir desses estudantes, os obstáculos de origens didática presente em aulas com predominância de metodologias únicas que não respeitam a heterogeneidade de uma sala de aula além da ausência de adaptações necessárias para atender as especificidades do alunado e ainda os obstáculos que comprometem a inclusão de estudantes PAEE com limitações sensoriais, os quais convivem com excesso de informações visuais, no caso dos estudantes cegos.

Com respeito à disciplina de física é possível notar que tal disciplina já é historicamente encarada pelos estudantes como uma das mais complexas devido sua estrutura composta de equações, simbologias e abstração. Essa complexidade pode ser resultado de uma série de fatores que acompanham o ensino tradicional de física. Um dos fatores que pode contribuir com essa visão são os currículos descontextualizados apresentados aos estudantes do ensino médio. A abordagem dos conteúdos faz com que tal disciplina seja vista como uma ciência que finalizou no século passado, sendo que as novas descobertas e até mesmo as aplicações de descobertas antigas não faz parte da maioria dos currículos de física no ensino médio atual. Outro problema que pode ser identificado é o excesso de cálculos que compromete o interesse do estudante pela disciplina de física, é compreensível tal repulsa visto que torna-se desmotivante uma quantidade excessiva de cálculos, sem que haja discussões do significado físico para permitir a compreensão qualitativa dos resultados numéricos.

Para além desses fatores usuais que comprometem o aprendizado da física, os estudantes cegos ainda encontram-se sujeitos às dificuldades oriundas da falta de acessibilidade do conteúdo apresentado nas aulas, cuja organização é quase que exclusivamente visual. Expressões como: "Essa é a trajetória desse objeto" ou ainda "A intensidade da força exercida no bloco vermelho é maior do que a exercida no bloco azul" carregam informações de natureza puramente visual e comprometem assim a apreensão das informações pelos estudantes cegos. 
Nas aulas de física uma barreira de natureza exclusivamente visual tem sido o uso de ilustrações construídas na lousa pelo professor ou impressas no livro didático, que representam situações físicas ou aparatos experimentais. Tais ilustrações representam um recurso importante no processo de ensino/aprendizagem do conteúdo de física, visto que na ausência de laboratórios equipados são essas ilustrações que levam até a sala de aula situações físicas materialmente inacessíveis.

Nesse contexto os estudantes com cegueira podem enfrentar muitas dificuldades quando inseridos no ensino regular porque o aprendizado de física está relacionado ao uso de quadro, slides, filmes, diagramas, e outros recursos de natureza visual (SEVILLA et al., 1991). Um grande desafio é, portanto, tornar acessível uma aula de física cujas informações são predominantemente visuais. Dessa forma, adaptações que possibilitem o acesso ao currículo escolar por meio de outros sentidos que não seja o sentido da visão tornam-se indispensáveis para o processo de ensino e aprendizagem de estudantes cegos.

No caso do ensino de física a literatura brasileira apresenta algumas propostas interessantes para construção de materiais didáticos destinados ao ensino da física aos estudantes com cegueira, (ver, por exemplo, CAMARGO, 2007, 2008; DOMINICI, 2008) e que podem ser usados por professores durante suas aulas. A ideia geral de vários recursos apresentados na literatura consiste em transpor em relevo as representações visuais usadas em aulas de física do ensino médio. Geralmente são apresentadas representações bidimensionais táteis buscando similaridade às ilustrações disponíveis em livros didáticos de física e aquelas construídas na lousa pelo professor. A proposta desse tipo de recurso é muito válida, porém pode-se elencar algumas limitações apresentadas em recursos como estes. O primeiro deles são os materiais usados para a construção do relevo, que geralmente usa-se o barbante, cola em relevo, cola quente, papéis texturizados, isopor, entre outros. Materiais como estes apresentam durabilidade reduzida e, com o tateamento constante pelo estudante cego, podem se degradar com facilidade. Além disso, pode-se notar que tais adaptações são, normalmente, confeccionadas com um propósito definido limitando assim um único recurso para determinado tópico de aula. Dessa forma vários recursos deveriam ser confeccionados para atender a variedade de conteúdos presente no currículo atual de física.

As limitações discutidas acima subsidiaram a idealização que resultou no desenvolvimento de um kit didático, denominado de KitFis, que propõe reproduzir tatilmente ilustrações de física similares às encontradas em livros didáticos de física do ensino médio. 
O KitFis encontra-se atualmente depositado no Instituto Nacional de Propriedade Industrial (INPI).

\section{O KitFis}

O KitFis é um material de apoio em aulas de física que se propõe a reproduzir tatilmente ilustrações de situações e fenômenos físicos. O kit é composto por 83 peças de diversos formatos e tamanhos e uma placa magnetizada. As peças podem ser fixadas na placa magnética por ação de uma imantação. Com as devidas combinações das diferentes peças pode-se construir e manter fixa na placa magnetizada diversas ilustrações táteis de fenômenos e situações físicas. A imantação da placa retangular é forte suficiente para manter as peças fixas durante o tateamento do estudante, porém apresenta uma imantação que permite a remoção e manipulação das peças de forma a construir as ilustrações. As peças possuem um relevo significativo que ao serem tocadas permitem a percepção da forma.

A quantidade e o formato das peças foram definidos a partir do estudo de ilustrações de vários livros didáticos de física de modo a permitir versatilidade na montagem das diferentes ilustrações de fenômenos físicos e aparatos experimentais utilizados em aulas de física.

O KitFis permite a construção de várias ilustrações de situações e fenômenos físicos que podem ser modificados e manipulados simultaneamente ao momento de uma aula, permitindo que o estudante cego participe ativamente da construção de seu conhecimento. A figura 1 apresenta algumas das ilustrações encontradas em livros didáticos de física que serviram de apoio para a construção das peças do KitFis.

Figura 1- Representações de alguns fenômenos físicos e equipamentos presentes em livros didáticos. a) Formação de imagens em espelhos esféricos. b) Forças atuando em um corpo. c) Resistores

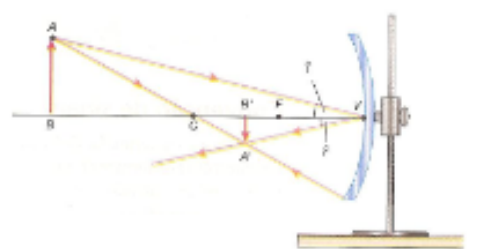

(A)

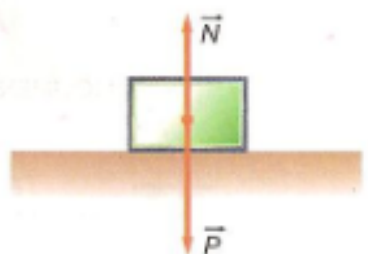

(B)

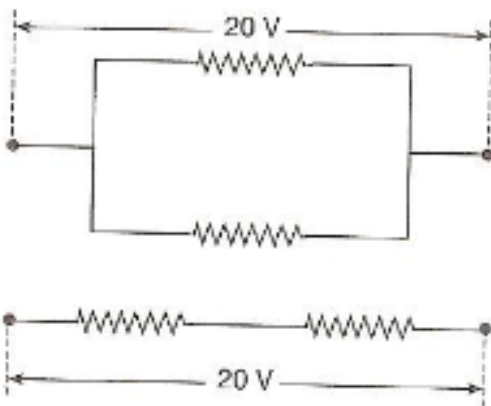

(C)

Fonte: MÁXIMO ; ALVARENGA, 2006. 
O kit apresenta funcionalidade similar da lousa, ou seja, a maioria das ilustrações que o professor constrói na lousa para os estudantes videntes podem ser construídas no KitFis de forma tátil. O KitFis pode agregar grande eficiência quando se pensa em inclusão escolar desses estudantes em aulas do ensino regular. Vale ressaltar que na ausência de materiais adaptados, informações visuais são apreendidas pelo estudante cego apenas pela audição, o que não é suficiente para o pleno aprendizado.

\section{Desenvolvimento}

O KitFis é resultado de uma pesquisa de mestrado de natureza qualitativa e exploratória, cujo objetivo foi desenvolver um kit didático que permitisse a reprodução tátil de imagens de Física apresentadas em livros didáticos do ensino médio. E além do desenvolvimento foi previsto também avaliar o protótipo do kit didático com aulas ministradas por professores licenciados em Física a estudantes com cegueira que cursem o ensino médio.

Para a realização dessa avaliação, foram convidados três professores licenciados em física e um estudante cego matriculado na rede estadual do estado de São Paulo. A dinâmica da avaliação envolveu a elaboração e ministração de uma aula para o estudante cego. O tema da aula ficou a escolha dos professores, a única exigência era que como apoio fosse usado o KitFis. O professor Daniel elaborou e ministrou uma aula sobre tópicos de Termodinâmica, o professor Eduardo sobre Leis de Newton e o professor Jean sobre alguns conceitos de Ótica. Todos os nomes dos participantes apresentados são fictícios e a pesquisa foi aprovada pelo comitê de ética em pesquisas com seres humanos além disso todos os participantes assinaram o termo de consentimento livre e esclarecido.

Cada aula ocorreu em dias diferentes e tiveram uma duração média de 40 minutos. As três aulas foram filmadas e todos os diálogos ocorridos durante as filmagens foram transcritos para análise. Foram selecionados trechos das aulas ministradas pelos professores em que eles construíram ilustrações no KitFis. Tais trechos foram analisados com o intuito de identificar as características funcionais do kit. É importante destacar que em nenhum momento foi avaliado o aprendizado do estudante cego através do uso do kit ou a didática empregada nas aulas pelos professores. $\mathrm{O}$ foco foi analisar a funcionalidade do KitFis em uma aula de física. Os professores e o estudante foram entrevistados ao 
término das aulas, com o intuito de levantar suas percepções após o uso e manuseio do KitFis.

Apresenta-se a seguir como resultados desse estudo algumas das ilustrações que os professores construíram no KitFis durante suas aulas e os diálogos entre os professores e aluno em que as características do kit ficavam evidentes.

\section{Resultados e Discussões}

Várias ilustrações foram construídas durante as aulas dos três professores e duas características do kit ficaram evidentes durante as filmagens e diálogos. Uma dessas características foi a versatilidade, pois o KitFis permitiu a construção de várias ilustrações de temas de física, além de permitir que essas ilustrações fossem modificadas durante o momento da aula sem que fosse necessário outro recurso didático. A qualidade tátil foi outra característica destacada, isso porque durante os diálogos é possível notar a percepção das peças pelo estudante cego.

$\mathrm{Na}$ figura 2 tem-se uma sequência de ilustrações construídas durante a aula ministrada pelo professor Daniel, na qual foram discutidos conceitos de pressão e variação de volume. O professor constrói uma representação de um êmbolo no interior de um cilindro, as partículas presentes nesse cilindro são representadas por pequenas peças no formato de quadrados. É interessante notar que após cada manipulação realizada pelos professores no kit, estes permitiam que o estudante tateasse tal ilustração de forma a perceber cada mudança e acompanhar os detalhes da construção da ilustração.

Figura 2- Partículas em um cilindro com um pistão móvel.
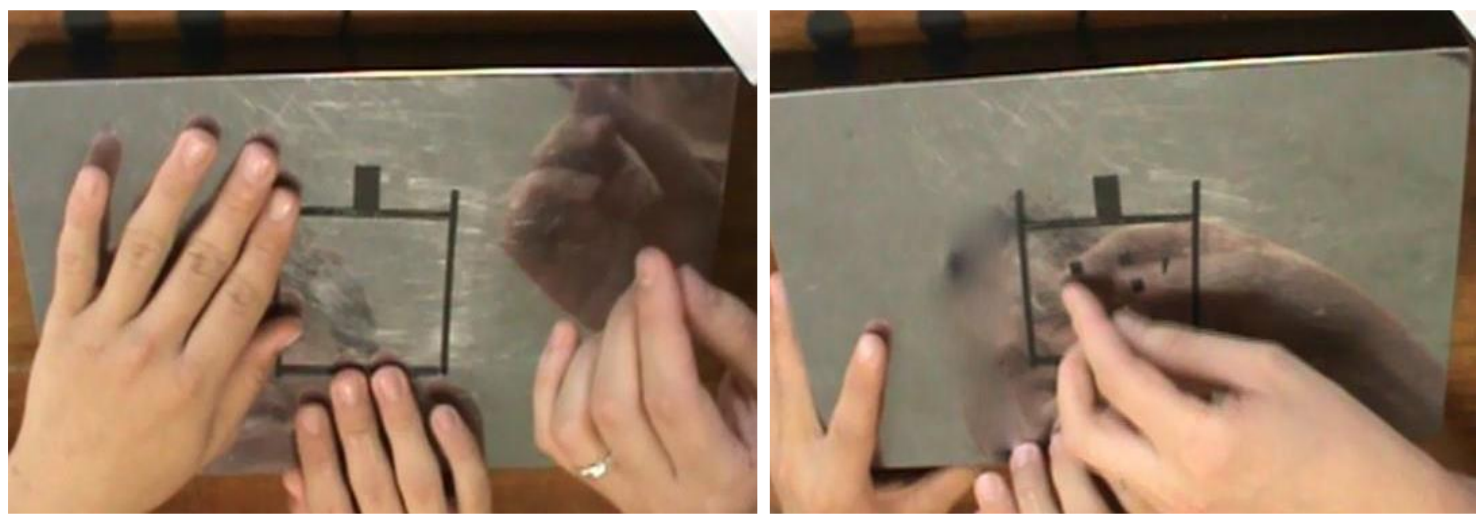


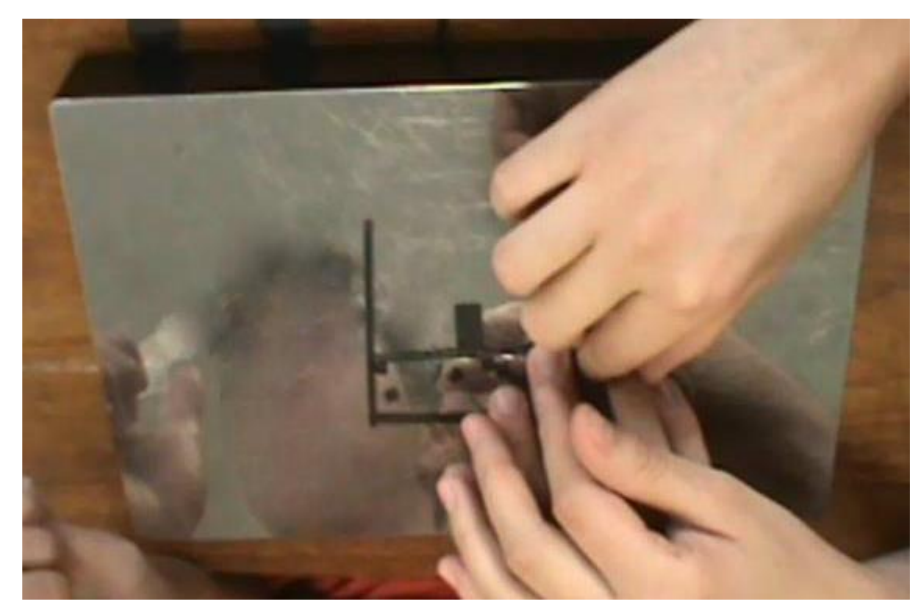

Fonte: Arquivo pessoal.

A construção dessas ilustrações ocorreu durante as explicações do professor sobre o tema da aula, ou seja, as modificações foram rápidas, assim como se fossem construídas em uma lousa na sala de aula. Nessa sequência destaca-se a característica de versatilidade presente no KitFis, pois o professor construiu uma ilustração e pôde modificála no momento em que a aula estava acontecendo. Nesse caso a modificação realizada foi a compressão do êmbolo, representando a diminuição do volume dentro do cilindro. 0 estudante pôde acompanhar essas modificações através do tato. Assim, em uma aula cujos estudantes são videntes as ilustrações e possíveis modificações realizadas pelo professor na lousa poderiam ser acompanhadas pelos estudantes visualmente. O estudante cego também poderá ter acesso a essa experiência juntamente ao seu professor, pois, o KitFis permite que o estudante cego acompanhe a construção de ilustrações através do tato.

Essa ilustração construída pelo professor Daniel pode ser encontrada de forma similar em livros didáticos de física como as representadas na figura 3.

Figura 3- Ilustrações de livros didáticos.
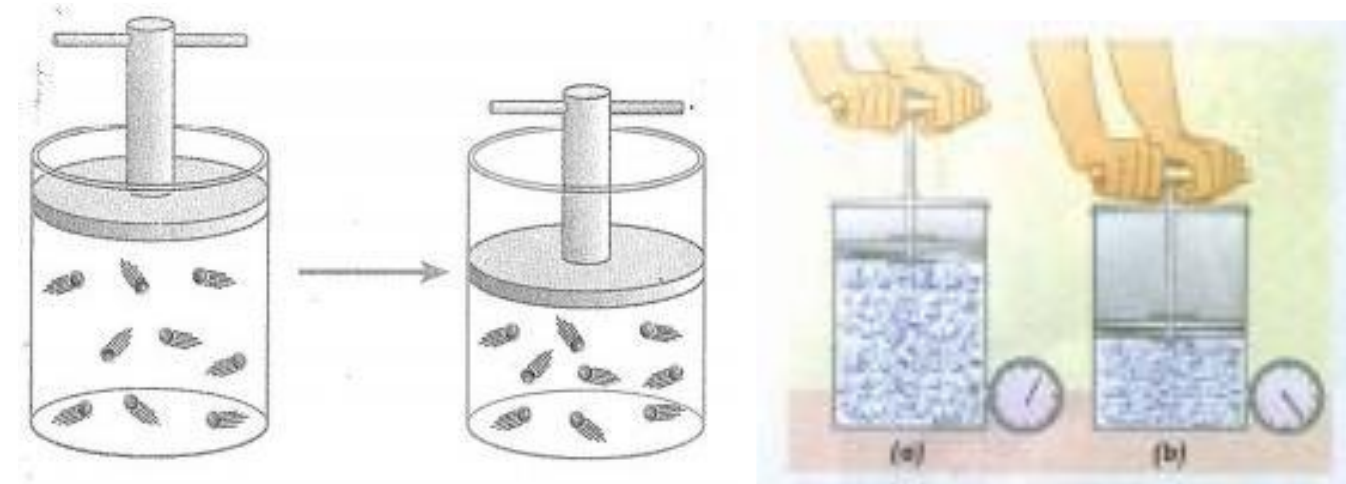

Fonte: a) NEWTON; HELOU; GUALTER, 2001. b) MÁXIMO; ALVARENGA, 2006. 
A característica de versatilidade também pode ser observada na sequência de aula apresentada na figura 4. Nessa aula o professor Jean discute conceitos de ótica geométrica, mais especificamente reflexão em uma superfície curva.

Figura 4- Reflexão da luz em uma superfície curva.
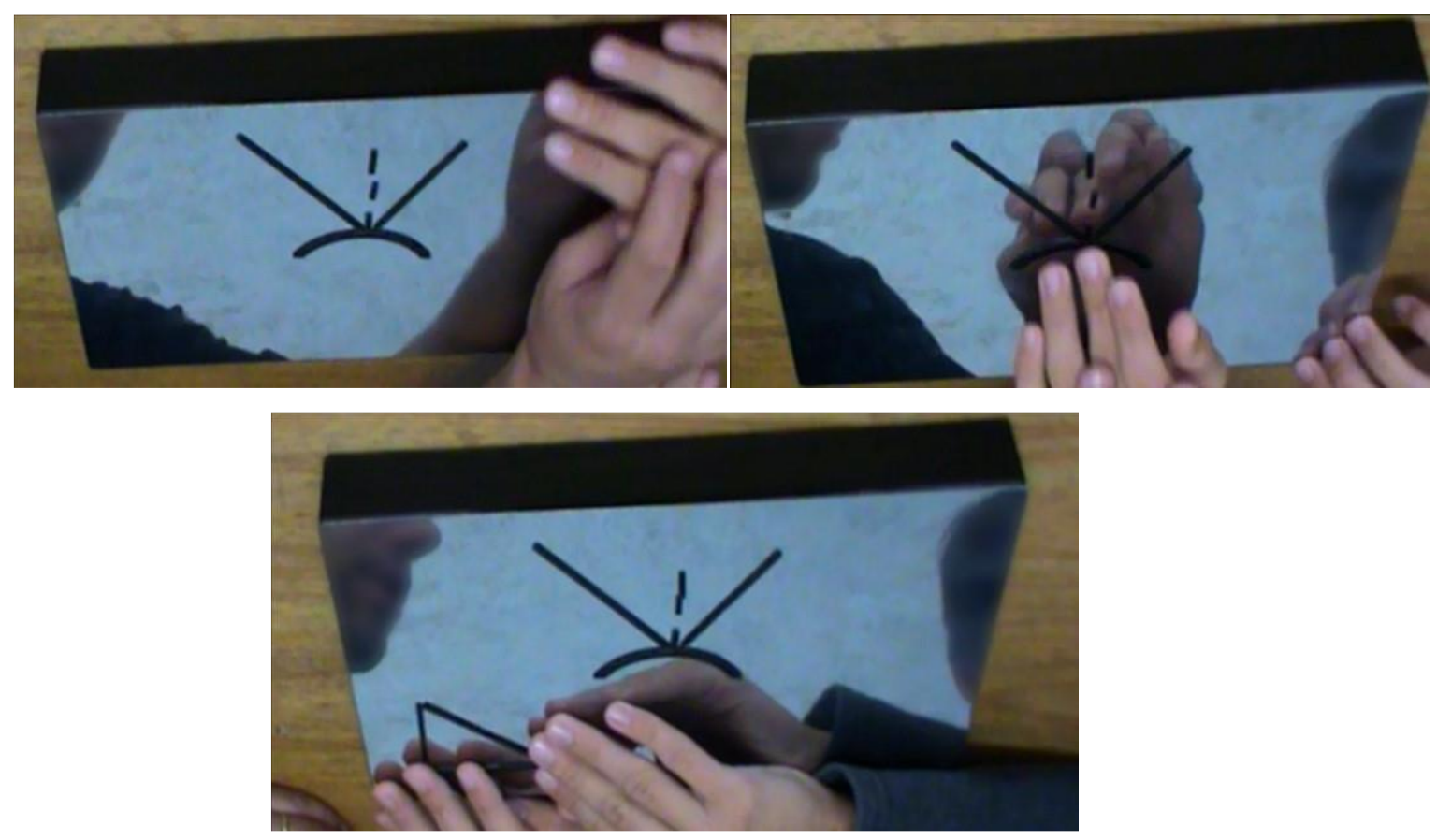

Fonte: Arquivo pessoal.

A representação apresentada na figura 5 é um exemplo de uma ilustração encontrada em livros didáticos de física similar à construída pelo professor Daniel no KitFis.

Figura 5- Representação no livro didático.

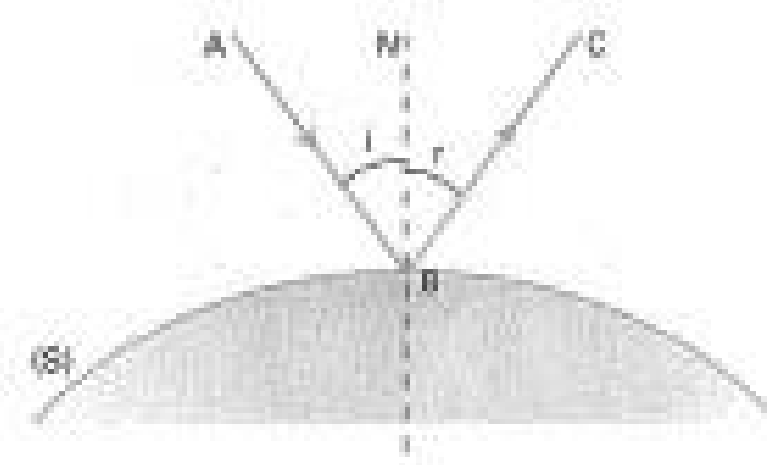

Fonte: GASPAR, 2005.

Num dado momento da aula o professor questiona o estudante sobre a definição de ângulos e ele não sabe responder. Se essa situação ocorresse em uma aula em que os 
recursos usados fossem os tradicionais confeccionados com colagens seria complicado 0 professor conseguir improvisar uma ilustração que o permitisse explicar ao aluno cego o que é um ângulo, visto que esses materiais exigem tempo prévio de preparo e, normalmente, não permitem modificações. Entretanto, com o uso do KitFis foi possível, sem desconstruir a ilustração principal, construir um triângulo retângulo (figura 4c) e explicar o conceito de ângulo para o aluno e prosseguir com a aula normalmente, sem a necessidade de recorrer a outros materiais.

A percepção da ilustração através do tateamento do estudante ficou evidente nesse momento da aula, como pode-se notar no diálogo entre eles:

Professor Jean: Aqui eu tenho uma superfície. Qual a característica dessa superfície?

Tiago: [...] ela faz uma curva.

Professor Jean: [...] aqui eu tenho uma superfície [...] tenho um feixe de luz incidente [...] está incidindo na superfície curva [...] e acaba sendo refletido...

Professor Jean: ...repare que eu tenho aqui um tracejado... Eles deveriam estar de uma forma alinhado [...] esse tracejado nós chamamos de normal, essa normal é perpendicular ao plano [...] e se eu pegar um ângulo... você tem ideia do que é um ângulo?

Tiago: ...eu não vou saber te explicar.

Professor Jean: então eu vou montar aqui do lado uma figura geométrica. Vamos tentar ver o que é um ângulo primeiro, pra depois eu falar do ângulo de incidência.

Professor Jean: O que é essa figura geométrica?

Tiago: [...] Isso daqui é um triângulo?

Afirmações do estudante como: [...] ela faz uma curva. E: [...] Isso daqui é um triângulo? Comprovam que ele consegue perceber o formato das ilustrações e mostra que as peças possuem uma qualidade tátil perceptível.

$\mathrm{Na}$ sequência apresentada na figura 6 o professor Eduardo discutiu o deslocamento de um bloco no sistema de coordenadas. Novamente pelo diálogo entre o professor e o estudante notamos que através do tateamento o estudante consegue perceber a ilustração construída.

Figura 6: Deslocamento de um bloco no eixo x. Fonte: Arquivo pessoal.

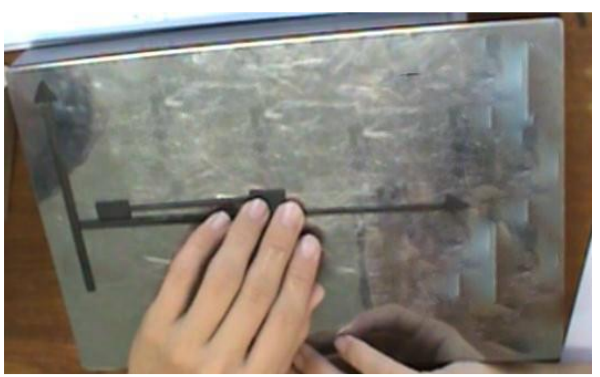

(A)

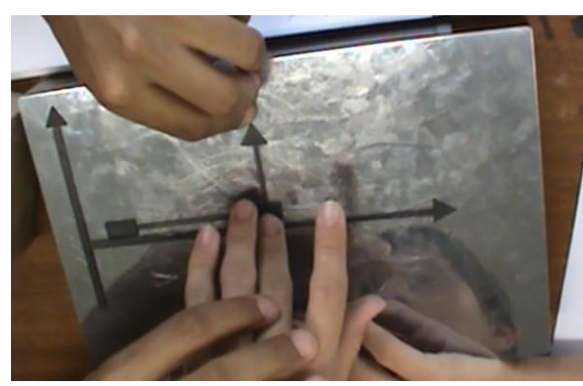

(B)

Professor Eduardo: Aqui nesse ponto em x, o que eu vou fazer? ... vou puxar ele, vou puxar nessa direção. (Ver figura 6b) 
Tiago: Ai você inverteu ele, ele está agora pra cima.

Professor Eduardo: Eu exerci uma força nessa direção. Como se tivesse empurrado ele pra cima.

Ao término das aulas de cada um dos professores foi realizada uma entrevista com cada um deles com o intuito de levantar suas percepções com relação ao uso e manuseio do KitFis. O estudante também foi entrevistado ao término das três aulas. Questionamos sobre o tamanho da mesa magnética e os participantes afirmaram que ela encontra-se em um tamanho adequado:

- Eu achei legal, ... portátil. [...]. O tamanho está legal ... pois se ficar maior e pesado fica ruim para levar (Professor Jean).

- Tá um tamanho excelente... tanto pra pegar... o tamanho do material está excelente para usar (Aluno Tiago).

- Eu acho que o tamanho parece ser adequado ... é um tamanho que cabe na carteira ... no tamanho da carteira da sala de aula, e é um tamanho que o aluno consegue transportar também. Não poderia ser um negócio muito grande porque dificultaria o transporte (Professor Daniel).

Quando questionado das peças o estudante participante ressalta a qualidade tátil das peças do kit:

- Dá para perceber muito bem (quando questionado a qualidade tátil das peças) [...] dá para ver bem o gráfico... dá para sentir bem (Aluno Tiago).

Os participantes forneceram ainda sugestões para aprimoramento do kit e as peças que o compõe:

- Dependendo da aula, um formato diferente assim, talvez em cinemática, por exemplo, no formato de carrinho, por exemplo, ou mesmo para conservação da quantidade de movimento, o carrinho ali serviria também pra você ver no caso colisões, né. Então não só no formato... ah é um carrinho, quando for falar de cinemática com ele, como ele se movimenta, melhor que um quadradinho, por exemplo, né, talvez ficaria mais interessante para ele. Talvez na área de eletricidade, resistores, um formato característico mais parecido. Dá para explicar pra eles com o que tem aqui, mas talvez seria mais próximo do o que a gente passa no quadro e tem nos livros (Professor Jean).

- Daria para fazer também uma adaptação para o braile, para colocar também algumas equações (Professor Eduardo).

No geral, nota-se que o kit possui uma boa aceitação por parte dos participantes que o avaliaram. As sugestões apresentação são válidas e podem contribuir para o processo de aprimoramento do protótipo do kit. Peças em formatos diferenciados que se aproximam da realidade são previstas para um aprimoramento no intuito de tornar as ilustrações construídas no kit mais contextualizadas. Além disso pode-se pensar na possibilidade de 
que o KitFis pode contribuir com o ensino de outras disciplinas que também possuem grande apelo visual.

\section{Conclusão}

As avaliações realizadas do KitFis ocorreram em situações extraclasse em que os professores não estavam sujeitos a pressão de vários estudantes na sala de aula e o dever de cumprir um horário e determinado conteúdo. Talvez esses fatores podem ter favorecido o pleno desenvolvimento dessas aulas individuais em que o KitFis foi usado. Dessa forma uma avaliação do uso do kit dentro de uma sala de aula convencional, com estudantes cegos e estudantes videntes, poderia ser realizada no intuito de verificar se os resultados obtidos com esse estudo de caso podem ser generalizados.

O foco central do estudo foi o de construir um kit didático que reproduzisse tatilmente ilustrações de fenômenos e situações físicas. Projetamos que esse kit deveria ser portátil, versátil e que as peças apresentassem qualidade tátil perceptível por um estudante cego. Através das filmagens das três aulas ministradas pelos professores as características de versatilidade e qualidade tátil puderam ser observadas.

A versatilidade foi uma característica possível de ser observada durante o andamento das aulas, isso porque o KitFis permitiu a construção de uma quantidade considerável de ilustrações de física, perpassando por temas distintos de física. Ilustrações de mecânica, de termodinâmica e de ótica geométrica puderam ser construídas. Dessa forma pode-se dizer que grande parte do conteúdo do currículo de física do ensino médio pode ser representado no KitFis.

A qualidade tátil ficou evidente durante as falas do estudante participante da pesquisa. Várias afirmações nos leva a considerar que o estudante percebeu as representações construídas pelos professores.

A portabilidade do kit é uma característica que os professores pontuaram durante as entrevistas realizadas com eles ao término de cada aula.

O KitFis permitiu que o estudante participasse ativamente da construção de cada ilustração, o que pode contribuir muito com o engajamento e a aprendizagem ativa do estudante, algo que não ocorre com os materiais tradicionais em que as ilustrações já são apresentadas prontas para uso. 
No momento as ilustrações bidimensionais e sem muitos detalhes são as mais recomendadas de serem construídas no KitFis, porém aprimoramentos já estão sendo pensados para atender uma maior variedade de ilustrações.

Entende-se que o KitFis pode ser um grande aliado ao processo de inclusão escolar de estudantes cegos em aulas de física no ensino regular. Uma vez que o ensino de física tem como forte recurso de ensino e aprendizagem as ilustrações, na ausência do sentido da visão essas ilustrações desfavorecem o aprendizado desses estudantes. O KitFis pode permitir ao estudante cego ter acesso através do tato às ilustrações presentes nos livros didáticos de física e aquelas construídas na lousa pelo professor, reforçando assim práticas inclusivas nas aulas de física. E por ser um kit que pode ser levado para a sala de aula, garante que o estudante cego esteja usufruindo do ambiente escolar da escola regular assim como os estudantes videntes.

O propósito de tornar acessível as representações visuais usadas nas aulas de física parte do pressuposto de que tais representações não são vazias de significado, pelo contrário, desempenham papel de fundamental importância para a construção do conhecimento físico. E na possibilidade de serem construídas de maneira tátil, tais representações podem continuar desempenhando seu importante papel no ensino de física, mesmo que para isso meio de apreensão dessa informação seja redirecionado para o tato.

A certeza de aprendizado por meio do KitFis não pode ser garantida visto que vários fatores podem comprometer o processo de ensino e aprendizagem, porém o kit pode garantir o acesso ao currículo que muitas vezes se apresenta como o maior obstáculo para a plena inclusão escolar desses estudantes.

\section{Referências}

BRASIL. Constituição da República Federativa do Brasil. Brasília, DF, 1988.

CAMARGO, E. P.; NARDI, R.; FILHO, P. R. P. M.; ALMEIDA, D. R. V. Como ensinar óptica para alunos cegos e com baixa visão. Física na Escola, v. 9, n. 1, 2008.

CAMARGO, E. P. É possível ensinar física para alunos cegos ou com pouca visão? Proposta de atividades de ensino de física que enfocam o conceito de aceleração.

Física na Escola, v.8, n. 1, p. 30 - 34, mai. 2007. 
DOMINICI, T.; OLIVEIRA, E.; SARRAF, V.; GUERRA, F. Atividades de observação e identificação do céu adaptadas às pessoas com deficiência visual. Revista Brasileira de Ensino de Física, v.30, n.4, p. 4501-2- 4501-8, 2008.

GASPAR, A. Física. São Paulo: ática. v. único. 2005.

INEP. Censo Escolar. Sinopse Estatística 2010, 2011, 2012 e 2013. Disponível em: $<$ http://portal.inep.gov.br/basica-censo-escolar-sinopse-sinopse>. Acesso em 29/10/2015.

MÁXIMO, A.; ALVARENGA, B. Física: ensino médio. São Paulo: Scipione, 2006.

NEWTON, V. B.; HELOU, D. R.; GUALTER, B. J. Tópicos em Física 2. São Paulo: Editora Saraiva, 2001.

SEVILLA, J.; ORTEGA, J.; BLANCO, F.; SÁNCHEZ, C. Physics for blind students: a lecture on equilibrium. Physics Education. v. 26, n. 4. p. 227 - 230, 1991.

\section{Correspondência}

Josiane Pereira Torres - Universidade Federal de São Carlos, Centro de Educação e Ciências Humanas, Departamento de Psicologia. Rodovia Washington Luís, Km 235. Monjolinho. CEP: 13565-905. São Carlos, São Paulo, Brasil. http://orcid.org/0000-0002-1825-0097

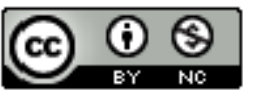

This work is licensed under a Creative Commons Attribution-NonCommercial 4.0 International (CC BY-NC 4.0) 